\title{
PARTICIPAÇÃO DOS PAIS NA TOMADA DE DECISÕES NO ATENDIMENTO ODONTOLÓGICO
} DE SEUS FILHOS

\author{
PARENT'S ROLE ON THE DECISION TAKING OF THEIR CHILDREN'S DENTAL TREATMENT
}

\author{
Monique Santos Machado* \\ Helen Cristhiane Muller Nagano ** \\ Juliana Yassue Barbosa da Silva *** \\ Vera Lúcia Bosco ****
}

\begin{abstract}
RESUMO
Introdução: Segundo o Código de Ética Odontológica, é considerada infração o atendimento de pacientes infantis sem o consentimento dos pais ou responsáveis, salvo em situaçôes de urgência. No tratamento odontopediátrico, é indispensável o esclarecimento dos pais em relação aos procedimentos a que seus filhos serão submetidos, as opçôes de tratamento existentes e seus custos, para que eles possam emitir um consentimento realmente esclarecido. O objetivo deste estudo é analisar se e de que forma os pais participam da tomada de decisões no atendimento odontológico de seus filhos. Para tanto, realizou-se uma pesquisa, utilizando-se um questionário, junto a 122 pais, cujos filhos tinham idades entre 0 e 6 anos e encontravamse matriculados em uma escola pública no município de Florianópolis. Verificou-se que 70,2\% dos pais autorizaram o tratamento de seus filhos de forma verbal, apenas 5,3\% deles assinaram um Termo de Consentimento Livre e Esclarecido e 61,6\% náo receberam opçóes de tratamento. Concluiu-se que a postura paternalista do profissional, tem imperado também nos consultórios odontopediátricos, onde as decisóes deveriam ser compartilhadas com os responsáveis legais pela criança.
\end{abstract}

DESCRITORES: Bioética • Odontopediatria • Consentimento dos pais.

\section{ABSTRACT}

Introduction: According to the Brazilian Dental Ethical Code it is considered an infration to treat children without parents or guardians consent except in emergencial needs. On pediatric dental treatment it is mandatory that parents should be informed about the procedures that their children will receive as well as treatment options and their costs to allow them to emit a clarified consent. The aim of this study is to analyse if and how parents participate on decisions about their children's dental treatment. It was used a questionnaire to 122 parents or guardians, of children between 0 and 6 years of age, attending a public school in Florianópolis. 70,2\% of parents did authorize orally dental treatment of their children, only 5,3\% signed a written consent and $61,6 \%$ did not receive treatment options. It was concluded that paternalist posture is still present nowadays in dental pediatric office, where children's treatment choices should be shared with parents.

DESCRIPTORS: Bioethics • Pediatric dentistry • Parental consent.

* Acadêmica de odontologia da Universidade Federal de Santa Catarina (UFSC). mozinha_fpolis@hotmail.com

** Doutoranda em Odontologia em Odontopediatria pela Universidade Federal de Santa Catarina (UFSC). helen.nagano@hotmail.com

*** Mestranda em Odontologia em Odontopediatria pela Universidade Federal de Santa Catarina (UFSC). juyassue@hotmail.com

**** Professora Adjunta IV do Departamento de Odontopediatria da Universidade Federal de Santa Catarina (UFSC). bosco@ccs.ufsc.br 
Machado MS, Nagano HCM, Silva JYB, Bosco VL. Participação dos pais na tomada de decisões no atendimento odontológico de seus filhos. Revista de Odontologia da Universidade Cidade de São Paulo 2009 jan-abr; 21(1): 38-47

\section{INTRODUÇÃO E REVISÃO DA LITERATURA}

Nascida no início dos anos 70 nos Estados Unidos, a Bioética ganhou um espaço incomensurável por designar um novo âmbito de pertinência em que se entrecruzam aspectos teóricos e práticos relativos às açóes humanas no campo das ciências e técnicas da vida e da saúde. Portanto, sua área de atuação deve ser considerada mais vasta do que a da tradicional ética médica, pois se preocupa com ações, situaçóes e consequências que podem transformar, de maneira irreversível, a própria estrutura de qualquer ser vivo e seus contextos bioecológicos (Barboza $\left.^{3}, 2005\right)$.

A necessidade de uma teoria acessível e prática visando orientar os profissionais da saúde ao desenvolvimento de uma conduta ética (ou bioética) deu origem à Teoria Principialista, baseada em quatro princípios que são: a beneficência, a não-maleficência, a autonomia e a justiça. (Kipper, Clotet ${ }^{15}$, 1998; Garbin et al' ${ }^{12}$ 2002; Azevedo Coutinho ${ }^{2}$, 2005). Sinteticamente:

Beneficência: refere-se à obrigação ética de fazer o bem. Procura maximizar os benefícios e minimizar danos ou prejuízos.

Não-maleficência: preconiza não fazer o mal e, junto com o princípio anterior, proíbe infligir danos deliberadamente.

Justiça: refere-se ao ato de dar a cada pessoa o que lhe é devido, tratando cada um de acordo com o que é moralmente certo ou adequado numa situação específica. É dar a cada um, conforme sua necessidade.

Autonomia: pressupóe que a pessoa é livre para fazer suas próprias escolhas desde que devidamente esclarecida. Deve ter liberdade de pensamento e estar livre de coaçóes para escolher entre as alternativas apresentadas. Se não há chance de escolha ou alternativa apresentada, não há o exercício da autonomia.

\section{Autonomia}

Semanticamente, autonomia vem do grego autonomia, composta pelo adjetivo pronominal autos, que significa "o mesmo", "eu" e nomos que significa "lei", "convenção". Nesse sentido, autonomia significa livre arbítrio, capacidade de tomar decisóes sem qualquer tipo de restrição ou coaçáo (Segre et al. ${ }^{24}, 1998$; Gonçalves $e t$ al. $\left.{ }^{14}, 2005\right)$; poder exercido com absoluta independência pelo sujeito (Marchi, Sztajn ${ }^{17}$ 1998).

A origem do princípio da autonomia remonta a aproximadamente 2500 anos, na expressão primum non noce- re, atribuída a Hipócrates, que afirmava que a prioridade maior era atribuir respeito pelo ser humano antes de se pensar em qualquer benefício que se possa fazer a, ou por ele (Leone $\left.{ }^{16}, 1998\right)$.

Apesar do princípio do respeito ao paciente estar sendo incorporado na área da saúde atualmente, este foi desrespeitado por muito tempo, principalmente devido ao modelo tradicional e paternalista desenvolvido pelos médicos e demais profissionais da área. Esse modelo era caracterizado pela relaçáo vertical entre profissional e paciente, onde o primeiro era detentor de todo o conhecimento e o segundo submetia-se ao tratamento eleito pelo profissional que o assistia (Gonçalves et $a l^{14}, 2005$ ).

Tratando-se de adulto, pessoa maior e capaz, a observância da sua vontade encontra amparo no principio bioético da autonomia, nos cânones do biodireito (Barboza $\left.^{4}, 2003\right)$ e no Código de Ética Médica, cumpridas que sejam as regras sobre a eficácia das declaraçóes de vontade e as limitaçóes estabelecidas à disponibilidade sobre o próprio corpo (Barboza $\left.{ }^{3}, 2005\right)$.

A questão cresce em complexidade se o paciente é criança ou adolescente, incapaz, portanto, (ainda que em estado de consciência), de se autodeterminar e de expressar sua livre vontade de forma válida. Além de indagar o que, quando e como fazer, impóe-se verificar se o procedimento cabível pode ser adotado, isto é, se o profissional tem o pleno poder de decisão ou se depende de autorização para adoção das práticas cabíveis. Os pais têm o poder para conceder tal autorização? Em qualquer caso? Para qualquer fim?

A lei brasileira, no que diz respeito à "capacidade natural de entendimento, inteligência e vontade própria da pessoa natural", estabelece duas categorias de pessoas humanas: 1) as capazes, ou seja, as que podem agir por si próprias, gerenciando seu corpo e seus bens; 2) as incapazes, isto é, pessoas a quem a lei não reconhece o poder de se autodeterminar, por força de uma das causas indicadas pelo legislador, como idade ou doença, e que dependerâo de outra que "decida", "fale", ou "atue" em seu lugar - em outras palavras, que as represente ou assista até que cesse a causa da incapacidade (Barboza $\left.{ }^{3}, 2005\right)$.

Em função da causa e da menor ou maior possibilidade de consciência dos seus atos, a lei considera absolutamente incapazes para os atos da vida civil: 1) menores de 16 anos; 2) os que, por sua enfermidade ou deficiência mental, não têm discernimento para tais atos e; 3) os que, mesmo por causa transitória, não possam exprimir 
sua vontade (Código Civil' ${ }^{6}$, 2002).

Assim cabe aos pais e/ou responsáveis assistir, criar e educar os filhos menores, competindo-lhes representálos até os 16 anos e assisti-los após essa idade, até os 18 anos, momento em que se tornam plenamente capazes para todos os fins de direito (Código Civil $\left.{ }^{6}, 2002\right)$.

\section{Termo de Consentimento Livre e Esclarecido}

O Código de Ética Médica ${ }^{7}$ (1988) estabelece ser vedado ao médico efetuar qualquer procedimento sem o esclarecimento e consentimento prévios do paciente ou de seu responsável legal, salvo iminente perigo de vida (art. 46). Pode-se identificar duas consequências diretas dessa orientação, que acabam por se imbricar: altera-se em parte a responsabilidade do médico e cresce a importância do consentimento livre e esclarecido, que assume papel de pressuposto para os procedimentos médicos, salvo havendo risco de vida (Barboza $\left.{ }^{3}, 2005\right)$.

$\mathrm{Na}$ área odontológica, segundo o Código de Ética Odontológica $^{8}$ (2003) constitui-se infraçáo ética o início do tratamento de menores sem a autorizaçáo de seus responsáveis ou representantes legais, exceto em casos de urgência ou emergência (Código de Ética Odontológi$\left.\mathrm{ca}^{8}, 2003\right)$.

Logo, ao se considerar que a clínica odontopediátrica tem como seu principal foco crianças e adolescentes menores de 16 anos, portanto, legalmente incapazes de tomar qualquer decisão a seu próprio respeito, faz-se necessária a autorização do seu responsável para que qualquer ato profissional seja praticado (Walker, Ferreira ${ }^{26}$, 2002).

O termo de consentimento livre e esclarecido é um documento através do qual o profissional informa, de maneira clara e com linguagem acessível à pessoa leiga, o procedimento proposto, a forma e o tempo de seu desenvolvimento, os desconfortos e riscos a serem enfrentados, os possíveis benefícios ou malefícios, os métodos alternativos existentes e os custos, por exemplo. Enfim, tudo o que razoavelmente possa interferir na decisão, não sendo aconselhável adotar-se um padrão ante as inúmeras variáveis existentes. Dessa forma, o paciente é capaz de realizar uma escolha consciente e consequente (Muñoz, Fortes ${ }^{19}$, 1998; Gonçalves et al ${ }^{14}, 2005$ ).

O Código de Ética Odontológica também estabelece como infração ética o cirurgião-dentista deixar de esclarecer adequadamente os propósitos, riscos, custos e alternativas de tratamento ao paciente (Código de Ética Odontológica $\left.^{8}, 2003\right)$.
Existem dois tipos de consentimentos: o expresso e o implícito. O consentimento implícito é obtido através da análise do comportamento somado as atitudes do paciente durante o atendimento, quando o profissional presume que o mesmo está de acordo ou desacordo com o tratamento oferecido. $\mathrm{O}$ consentimento expresso pode ser escrito ou oral, e ocorre quando, após receber as orientaçóes sobre o tratamento que será realizado, o paciente e/ou responsável declara, de maneira escrita ou verbal, estar de acordo ou náo com o tratamento proposto pelo profissional.

É indispensável que o paciente seja capaz de compreender os esclarecimentos e de consentir. Juridicamente, em termos formais, em se tratando de crianças ou adolescentes, o consentimento será dado por seus representantes legais, normalmente os pais.

Parece razoável, no entanto, que, sempre que possível, se ouça a criança ou adolescente, respeitando sua vontade, desde que esta não agrave seu estado ou ponha sua vida em perigo. Em outras palavras, consideradas as condiçóes pessoais do paciente menor, (sua idade, capacidade de percepção e de cumprir as prescriçóes médicas), deve-se respeitar, o quanto possível e razoável, seu consentimento livre e esclarecido (Barboza $\left.{ }^{3}, 2005\right)$.

O limite da autonomia deve, portanto, ter uma avaliação contextual através da qual seja valorizado o momento de desenvolvimento em que se encontra a criança ou o adolescente, lembrando que esse é um processo dinâmico em que as habilidades, capacidades adquiridas e vivências são incorporadas dentro de uma evolução constante. Como essa evolução tem parâmetros conhecidos, passa até a existir certa previsibilidade nas modificaçóes que ocorrerão (Azevedo Coutinhoº ${ }^{2}$ 2005).

O ser humano em seu desenvolvimento na infância e na adolescência pode tomar decisóes baseadas no medo do desconhecido ou ditadas por um capricho da vontade ou, ainda, como fruto de uma reflexão amadurecida. E essa grande variação de fatores desencadeantes é que traz à tona toda a dificuldade envolvida quando se quer analisar a competência para decidir. O que os pais ou responsáveis e os profissionais de saúde devem considerar é a aplicação da legislação em consonância com a análise da autonomia da criança e do adolescente, procurando identificar se já adquiriram habilidade para entender as informações, a capacidade de realizar escolhas e o discernimento para avaliar o risco-benefício e os danos consequentes a de uma decisão tomada. 
Machado MS, Nagano HCM, Silva JYB, Bosco VL. Participação dos pais na tomada de decisões no atendimento odontológico de seus filhos. Revista de Odontologia da Universidade Cidade de São Paulo 2009 jan-abr; 21(1): 38-47

Cabe ao odontopediatra e aos demais profissionais da saúde, utilizando-se de suas competências profissionais, definir em qual estágio de desenvolvimento seu paciente se encontra e assim diferenciar se está diante de uma tomada de decisão ditada pelo medo do desconhecido, por uma vontade decorrente de uma visão egocêntrica comum em algumas faixas etárias ou se já é resultante de uma reflexão amadurecida. Deve ser incentivada a participação da criança e do adolescente na obtenção do consentimento esclarecido em conjunto com a família: a validade moral para tal ação virá à medida que seja adequado o processo ao estágio de desenvolvimento biopsicossocial dos menores (Leone ${ }^{16}, 1998$; Goldin $\left.{ }^{13}, 2004\right)$.

Técnicas de Controle do Comportamento Infantil e a Concordância dos Pais

Em odontopediatria, muitos são os fatores que podem influenciar de maneira negativa o tratamento, sendo o medo e a ansiedade os principais obstáculos para

Tabela 1 - Frequência absoluta e relativa das variáveis estudadas em crianças (0-6 anos), que já receberam atendimento odontológico, de uma pré-escola. Florianópolis, Santa Catarina, Brasil

\begin{tabular}{ccc}
\hline \hline Variáveis & \multicolumn{2}{c}{ Crianças } \\
\hline & $\mathrm{n}$ & $\%^{*}$
\end{tabular}

$\begin{array}{ccc}\text { Sexo } & & \\ \text { Masculino } & 50 & 47,6 \\ \text { Feminino } & 55 & 52,4\end{array}$

\section{Faixa Etária (anos)}

$\begin{array}{lll}\leq 5 & 68 & 74,7 \\ >5 & 37 & 25,3\end{array}$

Renda Familiar (Salários mínimos - SM)

$\begin{array}{ccc}\leq 3 \mathrm{SM} & 5 & 4,8 \\ >3 \mathrm{SM} & 100 & 95,2\end{array}$

\section{Local de Atendimento}

\begin{tabular}{ccc} 
Serviço Público** & 20 & 19,1 \\
Consultório Particular & 85 & 80,9 \\
\hline \hline
\end{tabular}

* Intervalo de confiança de $95 \%$.

** Inclui atendimentos realizados em unidades de saúde, hospitais públicos e clínicas-escola de faculdades de odontologia.

Nota: os valores $\mathrm{n}$ e as porcentagens se referem ao número de observações válidas para cada variável. o odontopediatra. O impacto emocional, os medos e as fantasias gerados a partir de uma experiência vivida, ou até mesmo relatada por alguém também podem interferir negativamente no momento em que a criança entra em contato com o ambiente odontológico. (Caraciolo e Colares 5 , 2004).

Durante o atendimento odontopediátrico, é relati-

Tabela 2 - Frequência absoluta e relativa das variáveis referentes ao último atendimento odontológico de crianças (0-6anos), de uma pré-escola. Florianópolis, Santa Catarina, Brasil, 2007.

\begin{tabular}{ccc}
\hline \hline \multirow{2}{*}{ Variáveis } & \multicolumn{2}{c}{ Pais } \\
& $\mathrm{n}$ & $\% *$ \\
\hline $\begin{array}{c}\text { Permaneceram dentro da sala durante } \\
\text { o atendimento }\end{array}$ & & \\
Não & 6 & 5,8 \\
Sim & 98 & 94,2
\end{tabular}

$\begin{gathered}\text { Receberam informaçóes relativas ao } \\ \text { tratamento a ser realizado }\end{gathered}$
\[ \begin{array}{ccc}\text { Não } & 3 & 2,9 \\ \text { Sim } & 100 & 97,1\end{array} \]

$\begin{array}{lll}\text { Receberam opçóes de tratamento } & & \\ \text { Não } & 61 & 61,6 \\ \text { Sim } & 38 & 38,4\end{array}$

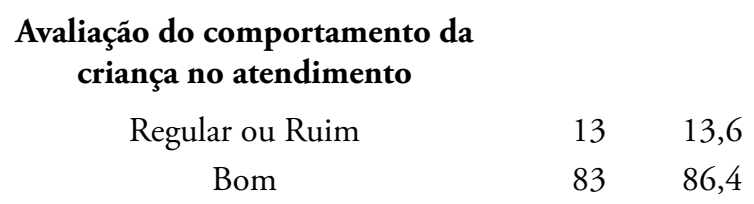

$\begin{gathered}\text { Assinaram algum documento } \\ \text { autorizando o tratamento (TCLE) }\end{gathered}$
\[ \begin{array}{ccc} & \\ \text { Não } & 89 & 94,7 \\ \text { Sim } & 5 & 5,3\end{array} \]

\begin{tabular}{|c|c|c|}
\hline $\begin{array}{l}\text { Autorizaram o tratam } \\
\text { de outra form }\end{array}$ & & \\
\hline Não & 28 & 29,8 \\
\hline Sim & 66 & 70,2 \\
\hline
\end{tabular}

* Intervalo de Confiança de 95\%.

Nota: os valores $\mathrm{n}$ e as porcentagens se referem ao número de observaçōes válidas para cada variável. 
vamente comum o emprego de técnicas de manejo do comportamento infantil. Em alguns pacientes, o emprego destas técnicas se faz necessário para a realização do tratamento. Em outros casos, elas são utilizadas apenas para desmistificar o tratamento odontológico e apresentá-lo de maneira positiva, reformulando imagens e associaçôes com experiências desagradáveis passadas (Mastrantonio et $\left.a l^{18}, 2004\right)$.

Tais técnicas podem ser divididas em farmacológicas (sedação consciente e inconsciente) e não farmacológicas, as quais podem ser classificadas ainda como positivas ou informativas (dizer-mostrar-fazer, reforço positivo, controle da voz e modelagem) e como negativas ou psicológicas aversivas (contenção física, mão sobre a boca e mão sobre a boca com restrição da respiração nasal) (Mastrantonio et al ${ }^{18}, 2004$ ).

Técnicas como a mão sobre a boca e a contenção física, por serem consideradas aversivas, devem ser utilizadas criteriosamente dentro de suas indicaçóes. Assim, a contenção física possui indicação para crianças menores de três anos ou para crianças com distúrbios mentais, sem capacidade de compreensão e que possuem comportamento relutante e histérico durante o tratamento odontológico. Já a técnica da mão sobre boca é bastante controversa e, quando indicada, é recomendada para pacientes saudáveis, acima de três anos de idade, capazes de compreenderem perfeitamente as orientaçóes dadas pelo cirurgião-dentista, mas que se comportam de maneira resistente ao atendimento (Tavares et al ${ }^{55} ; 2000$ ).

Enquanto o cirurgiāo-dentista emprega técnicas de controle do comportamento infantil baseado na sua experiência profissional, pequena atenção tem sido dada às atitudes dos pais a respeito do uso destas. (Amorim et al ${ }^{1}$,2003).

Um estudo realizado por Fuccio et al. ${ }^{11}(2003)$ analisou a aceitação dos pais em relação às técnicas de manejo do comportamento utilizadas durante o atendimento odontopediátrico. Os pais classificavam as técnicas após assistirem a uma gravaçáo áudio-visual de acordo com o grau de aceitação para execução em seus filhos. As mais aceitas foram: dizer-mostrar-fazer, controle de voz, reforço positivo e sedaçáo consciente, e em algumas situações os pais consideravam ainda a utilização de técnicas como - contenção ativa e passiva. A maior parte dos pais disse que nunca permitiria a execução de técnicas como mão sobre boca e anestesia geral, refletindo, segundo os autores, a necessidade de maior esclarecimento dos pais sobre a indicaçáo e o implemento de cada técnica.

O critério fundamental para aplicação dessas técnicas é a obtenção da permissão dos pais ou responsáveis pela criança através do termo de consentimento. Porém, segundo a literatura, a maioria dos profissionais que faz

Tabela 3 - Associação entre as variáveis referentes ao último atendimento odontológico e as variáveis sócio-demográficas na amostra de crianças (0-6 anos), de uma pré-escola em Florianópolis, Santa Catarina, 2007.

\begin{tabular}{|c|c|c|c|c|c|c|}
\hline Variáveis & $\begin{array}{c}\text { Permanência dos pais na sala de } \\
\text { atendimento }\end{array}$ & $\mathbf{n}^{*}$ & $\mathbf{p}^{* *}$ & & & \\
\hline & Sim & & & & & \\
\hline & $\mathrm{n}$ & $\%$ & $\mathrm{n}$ & $\%$ & & \\
\hline \multicolumn{7}{|l|}{ Sexo } \\
\hline Masculino & 44 & 86,3 & 7 & 13,7 & & \\
\hline Feminino & 55 & 100 & 0 & 0 & 106 & 0,004 \\
\hline \multicolumn{7}{|l|}{ Faixa Etária (anos) } \\
\hline$\leq 5$ & 65 & 94,2 & 4 & 5,8 & & \\
\hline$>5$ & 34 & 91,9 & 3 & 8,1 & 106 & 0,466 \\
\hline \multicolumn{7}{|l|}{ Local de Atendimento } \\
\hline Serviço Público & 20 & 95,2 & 1 & 4,8 & & \\
\hline Consultório Particular & 79 & 92,9 & 6 & 7,1 & 106 & 0,579 \\
\hline
\end{tabular}

* Número de observações válidas.

** Teste exato de Fischer. 
Machado MS, Nagano HCM, Silva JYB, Bosco VL. Participação dos pais na tomada de decisões no atendimento odontológico de seus filhos. Revista de Odontologia da Universidade Cidade de São Paulo 2009 jan-abr; 21(1): 38-47

uso dessas técnicas não obtém o consentimento prévio dos pais por escrito.

Em uma revisão de literatura realizada por Oliveira et al. ${ }^{21}$, (2001), sobre sedação durante o atendimento odontológico, os autores afirmam que o termo de consentimento assinado pelos pais é um documento a favor do profissional, e este, conhecendo os riscos que determinadas técnicas envolvem, deve relatar aos pais os objetivos, as indicaçóes e contraindicaçóes de maneira clara e de acordo com o grau de entendimento dos responsáveis pela criança.

É necessário, portanto, esclarecer os pais em relação aos procedimentos a que seus filhos serão submetidos, sanar suas dúvidas e explicar-lhes a necessidade de uso de técnicas de manejo comportamental, pois os pais são os agentes de saúde familiar responsáveis pela motivação essencial para o tratamento odontopediátrico. Assim, os pais ou responsáveis devem ser encarados como aliados na promoção da saúde oral da criança (Ramos-Jorge e Paiva $^{22}$; 2003; Noronha et al $\left.{ }^{20} ; 2001\right)$.

O presente estudo buscou analisar a conduta do cirurgião-dentista e a participaçáo dos pais na tomada de decisôes durante o atendimento odontológico de seus filhos.

\section{MATERIAIS E MÉTODOS}

A população deste estudo transversal, de caráter exploratório descritivo, constituiu-se de crianças com idades entre 0 e 6 anos, de ambos os gêneros, regularmente matriculadas em uma pré-escola no Município de Florianópolis, capital do Estado de Santa Catarina, localizado na Regiáo Sul do Brasil, em março 2007. A amostra foi intencionalmente escolhida por tratar-se de uma pré-escola que atende crianças de diferentes estratos sócioeconômicos e culturais, as quais devem frequentar diferentes tipos de serviços odontológicos (público, clínicas-escola e particulares). Inicialmente a pré-escola foi contatada por telefone, através do qual foi agendada uma visita das pesquisadoras ao local para a exposição da pesquisa. Após aprovação do colegiado escolar, e do Comitê de Ética em Pesquisa com Seres Humanos da Universidade Federal de Santa Catarina, foi dado início à fase de coleta de dados.

Os dados foram coletados através de um questionário autoaplicável padronizado, composto por 15 perguntas fechadas sobre a temática (Anexo 1). Este questionário foi enviado aos pais acompanhado de uma carta contendo explicações sobre a finalidade, os objetivos e a re- levância da pesquisa, além de duas cópias de um Termo de Consentimento Livre e Esclarecido (TCLE) através da agenda escolar da criança. Entre a entrega dos questionários e o seu recolhimento, aguardou-se o prazo de 3 dias. Dos 258 questionários enviados, 122 foram incluídos nas análises. Foram excluídos da amostra os questionários que não estavam adequadamente preenchidos ou acompanhados de cópia assinada do TCLE.

O armazenamento dos dados foi realizado no programa de domínio público EPIDATA versão 3.1 e as análises estatísticas foram realizadas através do software EPI-INFO versão 3.4 (Centers for Disease Control and Prevention, Atlanta, Estados Unidos). Para tanto, foi adotado o nível de significância $\mathrm{p}<0,05$ e intervalo de confiança de $95 \%$. Foi realizada a descrição das variáveis demográficas e de atendimento das crianças. $\mathrm{O}$ teste exato de Fischer foi utilizado para testar associação entre variáveis como permanência dos pais na sala de atendimento e renda, sexo e local de atendimento.

Para a realização dos testes de associação entre variáveis, algumas questôes do questionário foram reagrupadas. Na questão referente à idade, formaram-se dois grupos, o das crianças com até 5 anos e o das crianças com mais de 5 anos. A renda familiar das crianças também sofreu recategorização, sendo formados os grupos: renda menor ou igual a três salários mínimos e renda maior que três salários mínimos. A questão relacionada ao número de filhos do casal foi agrupada em duas novas categorias: um único filho e mais que um filho. Já a pergunta referente ao local do último atendimento odontológico da criança teve a categoria serviço público somada à categoria clínica-escola, sendo o atendimento particular a outra categoria. Outra questão que foi recategorizada foi referente ao comportamento da criança, que passou a ser considerado bom ou ruim (incluindo-se a categoria regular, que foi pouco representativa). Todos os reagrupamentos de variáveis foram efetuados com base na mediana das respostas obtidas.

\section{Consideraçóes Éticas}

O estudo foi realizado de acordo com os princípios éticos que constam na Resolução 196/1996 do Conselho Nacional de Saúde. A coleta de dados foi iniciada apenas após o recebimento do parecer favorável do Comitê de Ética em Pesquisa com Seres Humanos da Universidade Federal de Santa Catarina (UFSC), pelo parecer $n^{\circ}$. 170/06. Nos questionários, houve a preocupação com a não identificação dos pais ou da criança, o que possibili- 
Machado MS, Nagano HCM, Silva JYB, Bosco VL. Participação dos pais na tomada de decisões no atendimento odontológico de seus filhos. Revista de Odontologia da Universidade Cidade de São Paulo 2009 jan-abr; 21(1): 38-47

tou a manutenção do anonimato dos participantes.

\section{RESULTADOS}

Os resultados mostraram que a média de idade das crianças participantes da amostra foi de 4 anos e 3 meses. Com relação ao sexo, $52,4 \%$ das crianças eram do sexo feminino e, $47,6 \%$ do sexo masculino. $85,8 \%$ das crianças já tinham ido ao dentista. Destas, $80,9 \%$ tinham recebido o último atendimento odontológico em consultório particular, as demais $(19,1 \%)$, tinham recebido atendimento em unidade de saúde, hospitais públicos ou clínicas-escola de faculdades de odontologia. Os procedimentos mais realizados nessas crianças foram preventivos $(93,3 \%)$, restauradores $(9,5 \%)$ ou emergenciais $(6,7 \%)$. É importante salientar que na última visita ao dentista, uma mesma criança pode ter sido submetida a mais de um procedimento odontológico, por isso a soma dos percentuais não corresponde a $100 \%$. Na Tabela 1 , são apresentadas as frequências absolutas e relativas de algumas variáveis estudadas.

A maioria dos pais ou responsáveis $(94,2 \%)$ permaneceram junto com seus filhos, dentro do consultório odontológico, durante o atendimento. Com relação às informações acerca do tratamento odontológico a ser realizado na criança, 97,1\% dos pais afirmaram ter recebido informaçôes, porém, $61,6 \%$ deles não receberam opçóes de tratamento. $70,2 \%$ dos pais autorizaram o tratamento ou técnica executados em seus filhos de forma verbal e somente 5,3\% assinaram um Termo de Consentimento Livre e Esclarecido antes do início do tratamento. O comportamento da criança foi avaliado como bom por $86,4 \%$ dos acompanhantes, o que justifica o fato de somente $7,6 \%$ delas terem necessitado de contenção física durante o atendimento. $\mathrm{O}$ comportamento da criança foi classificado como regular ou ruim por $13,6 \%$ dos pais e somente $1 \%$ delas necessitou de ansiolíticos previamente ao atendimento, não sendo relatado o uso de outras técnicas aversivas de manejo do comportamento infantil. A Tabela 2 traz as frequências absolutas e relativas das variáveis referentes ao último atendimento odontológico da criança.

A associação entre a permanência dos pais na sala de atendimento odontológico e algumas variáveis demográficas é apresentada na Tabela 3 . O sexo da criança foi estatisticamente associado à permanência dos pais na sala de atendimento odontológico $(\mathrm{p}<0,05)$. Para as demais variáveis (faixa etária e local de atendimento), não foi observada associação. O teste de associação foi realizado ainda entre outras variáveis, porém, não foi observada associação estatisticamente significativa, o que provavelmente ocorreu em decorrência do tamanho da amostra.

\section{DISCUSSÃO}

A permanência dos responsáveis durante a consulta odontológica da criança pode influenciar no controle do comportamento infantil, surgindo assim, um tema que gera opinióes divergentes tanto entre os odontopediatras, como entre os pais (Ferreira e Colares ${ }^{10}, 2006$ ). Porém, a partir da década de 90, houve uma maior flexibilização dos cirurgiôes-dentistas em relação à presença dos pais durante o atendimento odontológico infantil. Algumas pesquisas recentes refletem essa mudança na postura do profissional, como a realizada por Ferreira e Colares ${ }^{10}$, em 2006 , que verificaram que $85 \%$ dos profissionais permitem que o responsável permaneça na sala de atendimento clínico durante o atendimento da criança. A literatura atual também mostra que a maioria dos pais preferem acompanhar as intervenções realizadas em seus filhos, como no estudo de Ribeiro Júnior et a ${ }^{2}$, 2002, em que $82,7 \%$ dos pais consideraram importante a sua permanência durante o atendimento infantil. Esses achados concordam com o resultado obtido neste estudo, onde se verificou que $94,2 \%$ dos responsáveis permaneceram junto com os filhos na sala de atendimento clínico, independentemente da idade da criança e do local de atendimento. No entanto, com relação ao sexo da criança, houve associação estatisticamente significativa entre a permanência dos pais na sala de atendimento odontológico e crianças do sexo feminino $(\mathrm{p}<0,05)$, como mostra a Tabela 3.

No que se refere ao recebimento de informaçóes sobre o tratamento odontológico a ser realizado na criança, a maioria dos pais $(97,1 \%)$ afirmou ter recebido informações a respeito. Esse achado mostrou-se superior ao encontrado por Garbin $e t a l^{2}$, em 2002, em que apenas $50,5 \%$ dos responsáveis receberam informaçóes acerca do tratamento. No entanto, quando questionados a respeito do recebimento de opçóes de tratamento odontológico para os filhos, somente $38,4 \%$ relataram as terem recebido, coincidindo com o resultado de Garbin $e t a l^{2}$, 2002, em que $34,02 \%$ dos pais participaram das decisóes do tratamento odontológico realizado na criança. Uma maior participação dos pais nas decisóes sobre o atendimento odontológico dos filhos poderia gerar resultados positivos, pois de acordo com Feigal $^{9}$ (2001), isto cria um maior comprometimento da família no tratamento 
Machado MS, Nagano HCM, Silva JYB, Bosco VL. Participação dos pais na tomada de decisões no atendimento odontológico de seus filhos. Revista de Odontologia da Universidade Cidade de São Paulo 2009 jan-abr; 21(1): 38-47

odontológico infantil.

Quanto à autorização do tratamento odontológico da criança, $70,2 \%$ dos pais o fizeram de forma verbal, e apenas 5,3\% deles assinaram um Termo de Consentimento Livre e Esclarecido. A assinatura desse documento pressupóe que o responsável recebeu informaçôes sobre os riscos, benefícios e alternativas de tratamento e, devidamente esclarecido, consentiu com o tratamento odontológico proposto pelo cirurgião-dentista. Desse modo, é possível verificar que houve uma violação ao direito dos responsáveis de serem agentes ativos no tratamento dos filhos e negligência por parte dos profissionais.

De acordo com os responsáveis, $86,4 \%$ das crianças apresentaram bom comportamento durante o atendimento odontológico, provavelmente devido à maioria ter sido submetida a tratamentos odontológicos preven- tivos $(93,3 \%)$.

\section{CONSIDERAÇÕES FINAIS}

A atitude paternalista do cirurgiáo-dentista, na qual se estabelece uma relação vertical em que o profissional é detentor do conhecimento, tem imperado também nos consultórios odontopediátricos. Os odontopediatras deveriam utilizar o Termo de Consentimento Livre e Esclarecido para o compartilhamento de informaçóes, decisóes e responsabilidades com os pais ou responsáveis legais pela criança, acerca do atendimento odontológico dos filhos. Além disso, os pacientes infantis, sempre que possível, deveriam ter as suas opinióes e anseios ouvidos com atenção, para se obter um maior engajamento ao tratamento e se garantir respeito ao princípio bioético da autonomia.

\section{ANEXO 1}

Questionário da pesquisa:

\section{Participaçáo dos pais na tomada de decisóes no atendimento odontopediátrico.}

As questôes abaixo são relacionadas ao seu filho que estuda no Núcleo de Desenvolvimento Infantil (NDI).

Idade da criança:
( ) até 1 ano
( ) entre 1 e 2 anos
( ) entre 2 e 3 anos
( ) entre 3 e 4 anos

( ) entre 4 e 5 anos

( ) entre 5 e 6 anos

( ) entre 6 e 7 anos

Sexo da criança:

( ) masculino ( ) feminino

Renda da família:

( ) menos de 1 salário mínimo ( ) entre 1 e 2 salário mínimos

( ) entre 2 e 3 salário mínimos ( ) mais que 3 salários mínimos

Número de filhos:

( ) 1 ( ) 2 filhos ( ) 3 filhos ( ) mais que 3 filhos

O seu filho que estuda no NDI é:

( ) seu único filho ( ) o filho mais velho ( ) o caçula ( ) filho do meio

Seu filho já foi ao dentista?

( ) $\operatorname{sim}($ ) não

A última vez que seu filho foi ao dentista, foi atendido em:

( ) serviço público (posto de saúde, hospital público) （ ) consultório particular （ ) clínica-escola (faculdades de odontologia, cursos de pós-graduação)

Que tipo de atendimento foi realizado em seu filho:

( ) preventivo (orientação, limpeza, flúor, selante) ( ) restauração (obturação)

( ) tratamento de canal ( ) extração de dente ( ) aten- 
dimento de emergência ( devido a quedas, acidentes de qualquer tipo)

Você e/ou seu (sua) esposo(a) permaneceram dentro da sala de atendimento durante o tratamento?

( ) $\operatorname{sim}($ ) não

Você e/ou seu (sua) esposo (a) receberam informaçôes sobre o tratamento que seria realizado?

( ) sim ( ) não

Foram apresentadas outras opçóes de tratamento em relação ao tratamento realizado?

( ) $\operatorname{sim}($ ) não

Durante este tratamento o comportamento do seu filho foi:

( ) bom ( ) regular ( ) ruim

O dentista usou algum destes métodos para controlar o comportamento?

( ) segurar a criança ( ) prender a criança para não se mexer

( ) colocar a mão sobre a boca da criança por causa do choro

( ) falar mais alto que a criança ( ) uso de óxido nitroso ("cheirinho")

( ) uso de remédios para acalmar ou adormecer a criança antes do tratamento

( ) anestesia geral (tratamento em hospital)

Você e/ou seu (sua) esposo (a) assinaram algum tipo de autorização para seu filho ser atendido (termo de consentimento livre e esclarecido ou outra forma de autorização por escrito)?

( ) sim ( ) não

Você e/ou seu (sua) esposo(a) autorizaram de alguma outra forma (verbal) o tratamento ou técnica?

( ) sim ( ) não

\section{REFERÊNCIAS}

1. Amorim RPB, Buto SO, Colares V. A concordância dos responsáveis com relação as técnicas de controle do comportamento do paciente infantil. J Bras Odonto-Pisicol Odontol. Pacientes Espec. 2003 Set-Out; 7(41): 427-31.

2. Azevedo AP. Bioética e pediatria. In: Scharamm, FR, Braz M. (Orgs). Bioética e saúde: novos tempos para mulheres e crianças? Rio de Janeiro: Fiocruz, 2005 p. 259-274.

3. Barboza HH. Bioética e biodireito: quem defende os interesses da criança?(6) 125-138p. In: Scharamm, FR, Braz M. (Orgs). Bioética e Saúde: novos tempos para mulheres e crianças? Rio de Janeiro: Fiocruz, 2005. p. $125-138$

4. Barboza HH. Princípios do biodireito. In: Novos temas de biodireito e bioética. Rio de Janeiro: Renovar, 2003.
5. Caraciolo G, Colares V. Prevalência de medo e/ ou ansiedade relacionados à visita do dentista em crianças com 5 anos de idade na cidade do Recife. Revista Odonto Ciência - Fac. Odonto PUCRS, 2004 Oct-Dez; 19(46): 348-53.

6. Brasil. Código Civil. Lei 10.406, 10 jan. 2002. São Paulo: Revista dos Tribunais, 2002.

7. Código de ética médica. Resolução do CFM n. 1.246/88, de 8 de jan. 1988. Disponível em: http:/ / www.portalmedico.org.br/codigo_etica/ codigo_ etica.aspe? portal. Acesso em: 15/04/2006.

8. Código de ética odontológica. Resolução do CFO n. 42, de 20 de maio de 2003. Disponível em: http:// www.ferp.usp.br/restauradora/etica/c_estica/ ceo_05_03.html. Acesso em: 15/04/2006. 
9 .Feigal RJ. Guiding and managing the child dental patient: a fresh look at old pedagogy. J Dent Educ. 2001 Dec; 65(12): 1369-77.

10. Ferreira AMB, Colares VA. participação do acompanhante durante o atendimento odontológico da criança nos serviços públicos na cidade do Recife. Rev Ibero-Am Odontopediatr Odontol Bebê. 2006: 9(47): 30-8.

11. Fúccio F, Ferreira KD, WatanabeSA, Jorge MLR, Pordeus JA, Paiva SM. Aceitação dos pais às técnicas de manejo do comportamento utilizadas em odontopediatria. J Bras Odontopediatr Odontol Bebe. 2003 Mar-Abr 6(30): 146-151.

12. Garbin CAS, Mariano RG, Machado TP, Garbin AJI. Estudo Bioético das relações humanas no tratamento odontológico. Rev Fac Odontol Lins 2002 Jan-Jul 14 (1): 54-9.

13. Goldim JR. Princípio do respeito à pessoa ou da autonomia. Disponível em: http:/ /www.bioetica.ufrgs. br/autonomi.htm. Acesso em: 15/05/2006.

14. Gonçalves PE, Garbin CAS, Garbin AJI. Quem deve escolher o tratamento: O paciente ou o cirurgião dentista? Uma reflexão bioética. FOA - Rev da Fac de Ondontologia Anápolis. 2005 jul/dez; 7(2): 23-5.

15. Kipper DJ, Clotet J. Princípios da beneficência e nãomaleficência. In: Ibiapina SFC, Garrafa V, e Oselka G. (Orgs.). Iniciação a Bioética. (Brasília) Conselho Federal de Medicina, 1998 pg. 37-52.

16. Leone CA. Criança, o adolescente e a autonomia. Revista Bioética, Brasília, 1998; 6(1): 51-4.

17. Marchi MM, Sztajin R. Autonomia e heteronomia na relação entre profissional de saúde e usuário dos serviços de saúde. Revista Biotécnica, 1998; 6(1): 3945.

18. Mastrantonio SDS, Gomes AC, Neves LT, Costa B. Manejo do comportamneto infantil no consultório Odonbtológico - Relato de Caso Clínico. J Bras Odontopediatr Odontol Bebê. 2004 Maio-Jun; 7(37): 230-7.
19. Muñoz DR, Fortes PA. C. O princípio da autonomia e o consentimento livre e esclarecido. In: Ibiapina SFC, Garrafa V. e Oselka G. (Orgs.) . Iniciação a Bioética. Brasília: Conselho Federal de Medicina, 1998 pg. 53-70.

20. Noronha JC, Ribeiro JRD, Souki BQ, Massara MLA. Parâmetros clínicos para a classificaçäo do estado motivacional familiar em Odontopediatria. J Bras Odontopediatr Odontol Bebe 2001 Jan-Fev; 4(17): 63-7.

21. Oliveira ACB, Pordeus IA, Paiva SM, Vale MPP. Sedaçäo: uma alternativa válida no controle de comportamento da criança durante o atendimento odontológico? Arq Odontol 2001 jan-jun; 37(1): 2534.

22. Ramos-Jorge ML, Paiva SM. Comportamento infantil no ambiente odontológico: aspectos psicológicos e sociais. J Bras Odontopediatr Odontol Bebe. 2003 janfev. 6(29):70-4.

23. Ribeiro Júnior HC, Oliveira ACB, Ferreira CM, Paiva SM, Pordeus IA. Opinião dos pais em relação a sua permanência durante o atendimento odontológico da criança. Arq Odontol; 2002; 38(4): 295-305.

24. Segre M, Silva FL, Schramm FR. O contexto histórico, semântico e filosófico do princípio de autonomia. Revista Bioética, Brasília, 1998; 6(1): 15-25.

25. Tavares MJ, Modesto A, Tostes Amaral MA, Rédua PCB, Vianna RCB. Avaliaçäo dos métodos de controle do comportamento infantil utilizados por dentistas enfatizando mäo sobre a boca e restriçäo física. Rev ABO Nac, 2000 out-nov; 8(5): 296-301.

26. Walker MMS, Ferreira SLM. Odontopediatria: uma visão sobre os aspectos éticos e legais. J Bras Odontopediatr Odontol Bebê, 2002 mar-abr; 5(24): 137-40.

Recebido em: 25/10/2007 Aceito em: 16/07/2008 